\title{
Supervision of learners with intellectual disabilities in a special school: In loco parentis of teachers as a wellness perspective
}

\author{
Rapeta Seshoka Joseph \\ Magano Meahabo Dinah \\ UNISA, South Africa
}

\begin{abstract}
This chapter addresses a study that was conducted at a special school for learners with intellectual disabilities in the Bojanala region of South Africa's North West Province. After all, the learners are the heartbeat of the school; in their absence, the school, its buildings and facilities, and even the teachers would be rendered pointless. The aim of this study was to explore ways in which learners are supervised and cared for, considering their mild, moderate and (in a few cases) severe intellectual disabilities. This longitudinal study took place over a period of three years and was embedded in a community engagement project conducted at a particular special school in said region. Due to the nature of a project, action research was selected as the approach most likely to yield useful results over an extended period of time. Additionally, Hettler's Wellness Theory (1980) was used as the theoretical framework by which to investigate how this school's teachers and other personnel adhered to the in loco parentis principle - i.e. teachers' legal imperative to assume some of parental functions and responsibilities, including protecting learners' physical and psychological wellbeing. As such, the school management team (SMT) and teachers made up the study's participants. Data were collected by means of questionnaires, interviews and observations. In their encounters with the school management team, the researchers realised that it is particularly crucial to ensure learner safety at special schools. Initial findings also revealed that most of the teachers employed at the school had not received training on teaching at a special school. Furthermore, teachers indicated that they were aware of their specific roles, stating that they only needed to be reminded of what they needed to do in order to ensure learner safety at all times. They pointed out that they simply followed the duty roster with regard to learner safety. This entails teaching learners about dangerous objects like garden utensils and how to remove them from the school premises in addition to adhering to the school safety policy. The teachers further revealed that 24-hour security personnel were employed by the school and that the school premises were bordered by a fence. Meanwhile, the SMT indicated that, although the school did have a safety policy, threats to learner safety persisted. For example, learners were not provided with protective equipment while working in the workshops. The SMT listed the potential consequences of this unsafe school environment as physical injuries, bullying, kidnapping, arson, harassment, and teen pregnancies. Since the study was transformative in nature and action research was relevant, there was a need for intervention. Thus, the findings of the study were shared with the SMT. Furthermore, it was clear from conversations with teachers that they needed intervention, including in-service training. The intervention process was discussed with the school management team and all staff members. It was patently obvious that the majority of the teachers and some of the management team did not have specialised training in special needs or inclusive education and that they were not aware of the needs of learners with intellectual disabilities. The SMT thus highlighted the need for training for all staff members in how to adhere to the in loco parentis principle.
\end{abstract}

Keywords: Intellectual disabilities, wellness, health promotion, safety, in loco parentis, supervision, bill of rights, professional teaching staff, behavioural problems, special school.

\section{Introduction}

Intellectual disabilities are defined by their advent during a crucial developmental period of the sufferer. They are characterized by sub-average intellectual functioning, with sufferers testing with Intelligent Quotient (IQ) scores of 70 below 
and demonstrating deficits in at least two areas of adaptive behaviour; i.e. communication, self-care, home living, social skills, self-direction, learning, leisure and work (Intellectual Disability Rights Service, 2009, pp. 1).

Meanwhile, education becomes meaningful only when learners, regardless of their intellectual capacity or abilities, are able to pursue their educational rights in an environment that is both safe and secure (Joubert, 2015, pp. 153). Public school educators are obligated to supervise learners for the full duration of the school day; this includes time spent participating in extra-mural activities. Moreover, extra care is needed when dealing with intellectually disabled learners since many of them, especially those suffering from autism, are unable to care for themselves as well as other children are able. As such, South African common law dictates that educators must assume the responsibility to care for children from their parents while they are at school or involved in official school activities. Note that educators are not expected or allowed to replace parents, but they are accountable for anything that happens to learners while they are at school. Roos, Oosthuizen and Smit (2009, pp. 126) posit that the in loco parentis principle obligates educators to carry out caring supervision over learners' the psychological and physical welfare, since they are impressionable and immature persons. In keeping with this, Coetzee (2007, pp. 74) argues that educators are vested with both "delegated" and "original" authority to take good care of the children placed in their charge. Teachers are supposed to ensure their duty of care on learners as bonus paterfamilias (i.e. to act as any reasonable person would act given the circumstances). This duty begins when the first learner arrives at the school in the morning and continues until the last learner has left the school in the afternoon. Geographically, the bounds of teachers' responsibilities extend to a few meters beyond the boundaries of the school premises; i.e. the immediate vicinity of the school.

\section{Theoretical Framework}

The perspective that guided the study in question was Hetler's (1980) Wellness Theory, as expounded on by Van Lingen (2000), which defines wellness as a continuous process of holistic development based on personally determined goals. Hetler (ibid.) adds that there are six dimensions pertinent to human development: physical, emotional, social, spiritual, intellectual and career wellness. According to Myers, Sweeney and Witmer (2000, pp. 252), meanwhile, wellness is:

A way of life orientated toward optimal health and well-being in which body, mind and spirit are integrated by the individual to live life more fully.

This theoretical framework was of great use to the researchers in the study at hand as it helped them to better understand the ways in which the SMT and teachers supported learners in their holistic development across all wellness dimensions. The framework also assisted researchers in identifying gaps in teachers' knowledge and skills, hindering their ability to provide adequate learner support.

\section{Legal Framework for Learner Safety}

In the Republic of South Africa, the supervision of learners with intellectual disabilities in special schools is governed by the following legal framework:-

\section{The 2007 United Nations Convention on the Rights of Persons with Disabilities and Optional Protocol}

The preamble to the United Nations Optional Protocol to the Convention on the Rights of Persons with Disabilities (2007) reaffirms that all human rights and fundamental freedoms as well as the needs of persons with disabilities are to be fully guaranteed without discrimination. In terms of Article 10 of this document (ibid) :

[The] parties reaffirm that every human being has the inherent right to life and shall take all necessary measures to ensure its effective enjoyment by persons with disabilities on an equal basis with others.

Moreover, Article 12 of the Optional Protocol to the Convention on the Rights of Persons with Disabilities (ibid.) holds that the life of a disabled person matters just as much as that of his or her able-bodied counterpart. In most circumstances, disabled children rely on able-bodied persons to assist them both mentally and physically to safely navigate dangerous environments. Unsafe environments therefore pose a particular threat to the disabled person's right to life.

2. The Constitution of South Africa, 1996

a. The right to education (Section 29) 
In terms of Section 29 of The Constitution of the Republic of South Africa (1996a), all South Africans have the right to basic education. This right can only be fulfilled in a safe school environment. The State must therefore ensure that public schools are free of drugs, weapons and other potentially dangerous elements. When Government fails in this mandate, many learners are forced to drop out of school to protect their own safety and are thus deprived of their right to basic education. Parents cannot be forced to enrol their children in schools where threats to their children's lives and wellbeing abound. Moreover, educators cannot provide learners with basic education if their own right to safety cannot be guaranteed.

\section{b. Equality (Section 9)}

The Constitution advocates the right to equal protection and benefit under the rule of law. Section 9(3) (Republic of South Africa, 1996a) states the following:

The State may not unfairly discriminate directly or indirectly against anyone on one or more grounds, including race, gender, sex, pregnancy, marital status, ethnic or social origin, colour, sexual orientation, age, disability, religion, conscience, belief, culture, language and birth.

Disabled children in South Africa are among those groups of people who qualify as previously disadvantaged. Therefore, as per the current dispensations affirmative action policy, special attention is paid to this group when it comes to matters such as employment and education to protect them against unfair discrimination. The Criminal Justice Support Network (CJSN) (2009) defines discrimination as follows:

[Discrimination] is treating a person, or group of people, less favourably than others would be treated in same circumstances because of their membership of a particular group, such as having a disability or being a woman.

Thus, any form of negligence in terms disabled children's safety on the part of educator may amount to unfair discrimination.

\section{c. Human Dignity (Section 10)}

Section 10 of The Constitution states that "everyone has inherent dignity and the right to have their dignity respected and protected" (Republic of South Africa, 1996a). Bullying and sexual violence violate the human dignity of disabled learners. Female learners, in particular, are often forced to drop out of school to escape violent school environments (Prinsloo, 2009, pp. 53). To combat this, user-friendly infrastructure and approachable social services personnel should be put in place to ensure safe schooling environments for disabled learners. The absence of such infrastructure and social services can be regarded as a serious infringement on the disabled learner's right to human dignity.

\section{d. The right to life (Section 11)}

Although Section 11 of The Constitution states that, "everyone has the right to life" (Republic of South Africa, 1996a), unsafe school environments continue to pose threats to the right to life of learners. For example, corporal punishment and bullying, among others, can be considered violations of this section. When learners are left unsupervised, the risk of them fighting and or otherwise injuring themselves becomes far greater. This is evidenced by the proliferation of media reports of stabbings, bullying, and rape in South African public schools over the past several years.

e. $\quad$ Freedom and Security of Person (Section 12)

In terms of Section 12 of The Constitution, the freedom and security of a person refers to their being safe from all forms of violence, torture, and cruel, inhuman and/or degrading treatment (Republic of South Africa, 1996a). This applies as much to intellectually disabled learners as to any other South African citizen. Thus, name-calling and other forms of degrading treatment and discrimination based on their disabilities amounts to infringement of this right.

\section{f. Privacy (Section 14)}

In terms of Section 14 of The Constitution, infringement on a person's right to privacy includes accessing their personal information in order to divulge it to third parties (Republic of South Africa, 1996a). The personal information of disabled learners is of a particularly sensitive nature and so must be handled with care in order to remain confidential, in keeping with this section of The Constitution. It is the responsibility of the school management team, together with the teaching staff, to ensure that learners' privacy is maintained. 
Nevertheless, it should be noted that, in terms of Section 36 of The Constitution, no right is absolute and can be limited provided the limitation is reasonable and justifiable (Republic of South Africa, 1996a). In all human rights, safety comes first. This simply means that an individual's right of to privacy can be limited if preserving this right may endanger the individual's safety or that of other citizens. For example, if it is suspected that a learner has brought drugs or weapons to school, their right to privacy must be infringed upon to enable a search of their person and property.

\section{g.}

\section{Safe environment (Section 24)}

Barry (2006, pp. 111) posits that the legal duty of care vested upon schools requires that they take action to prevent any foreseeable harm to learners in their charge. The SMT is responsible for drawing up a duty roster to ensure that all educators are involved in supervision. Such a roster will also serve as evidence of accountability in case of any incidents in which learners are harmed or threatened with harm.

\section{The South African Schools Act, 84 of 1996}

Section 8(a) of the South African Schools Act (84 of 1996) (Republic of South Africa, 1996b) advocates the search for and seizure of drugs and weapons in schools and other public areas. Moreover, the Minister of Education permits schools to utilise search devices for this purpose and to contact that South African Police Services (SAPS) to conduct random searches. In such cases, a police official may, without a warrant, conduct a search of any public school premises, provided there is sufficient reason to suspect the presence of such contraband. All people within the public school at the time of operation may be subjected to a search. Any weapons and/or drugs found during the search will be seized.

\section{The Regulations for Safety Measures at Public Schools (2001) as amended in 2006}

In 2001, the Minister of Education declared public schools to be violence- and drug-free zones in terms of Section 61 of the South African Schools Act (Republic of South Africa, 1996b). Safety measures must thus be in place in order for schools to remain free of drugs and other dangerous objects. These safety measures should be ensured in the school safety policy and should include the following:

a. People are prohibited from carrying dangerous objects onto the public school premises.

b. Illegal drugs are forbidden on the public school premises.

c. No person must be allowed to enter the public school premises under the influence of alcohol or drugs.

d. No form of violence or unrest will be allowed on public school premises.

In keeping with the South African Schools Act (Republic of South Africa, 1996b), school safety policies should also allow police officers to conduct random searches, as discussed under Point 3.

\section{The Children's Act, 38 of 2005}

The Children's Act, 38 of 2005 is derived from Section 28 of The Constitution, which holds that the best interests of the child are of paramount importance in all matters pertaining to the child. As such, Section 9 of the Children's Act (38 of 2005) (Republic of South Africa, 2005) states that in all matters concerning the care, protection and wellbeing of a child the child's best interests are of paramount importance. According to Joubert (2015, pp. 169), Section 10 of the Children's Act (Republic of South Africa, 2005) states that every child of such an age, maturity and stage of development as to be able to participate in any matter concerning that child, has the right to participate in an appropriate way, and that views expressed by the child must be given due consideration. In other words, within the context of this study, the law requires that the learner's voice be heard in all matters pertaining to his or her educational. Within this paradigm, it is clear that more serious attention needs to be paid to hearing the voices of intellectually disabled learners, lest their disabilities prevent them from effectively communicating their needs and desires.

\section{Research Methodology}

The study in question was embedded in a transformative-pragmatic paradigm, which employed both quantitative and qualitative methods for data collection. To ensure adherence to the relevant ethical considerations, the project was cleared by the University of South Africa ethics committee and the Bojanala regional office of the North West Province Department of Education. Participants included the school management team and teachers at a special school for learners with 
intellectual disabilities in that region. The researchers used questionnaires, interviews and observations for a data collection. Manual thematic content analysis, as outlined by Henning, Van Rensburg and Smit (2004, pp. 179), was used to analyse the data. Frequency tables were compiled based mainly on teachers' perceptions of how supervision was conducted at the school, whereas more in-depth data was obtained from both the SMT and the teachers. Out of this, the following themes emerged:

- Inadequately qualified educators;

- $\quad$ Safety concerns related to learner transportation;

- $\quad$ Safety concerns in workshops and the garden;

- $\quad$ The importance of effective feeding and health schemes;

- $\quad$ The need for a functional roster for playground supervision.

\section{Risk Environment}

\section{School Playground}

The school playground is the place where learners usually spend their leisure time during and after school hours. Schools are required to take reasonable steps to assess and respond to potential risks of harm to their learners (Barry, 2006, pp. 113 ) and this responsibility extends beyond the bounds of the classroom. School managers should ensure the presence of educators on the playground whenever they are in use by learners. Indeed, Joubert (2015, pp. 179) posits that the in loco parentis responsibility of educators starts from the time the learners enter the school premises and continues until the last learner leaves at the end of the school day.

\section{Sports Grounds}

Most school extra-mural activities take place on site on the school sports grounds, where injury in the normal course of play is inevitable for learners participate in school sports (Joubert, 2015, pp. 179) such as athletics, soccer, rugby, netball, cricket, and so forth. In light of this (and to prevent more serious injuries) educator supervision of the sports grounds supervision is essential. Such supervision is even more important in special schools, where disabled learners may be uniquely vulnerable to injury. In addition, all schools must obtain signed consent forms from parents before allowing learners to participate in school sporting activities. Joubert (2015, pp. 174) asserts that the following information should be included in such consent forms:-

1. The purpose of the school activity;

2. The nature of the school activity undertaken;

3. The full fixture of the school activity with the name of the supervising educator and his or her contact details;

4. The kind of transport, accommodation and food arrangements that have been made for away-from-school activities.

It is important to note that schools are not allowed to request parents to sign indemnity forms, exempting the school and educators from liability for damages. Such forms, even if they are signed by parents or learners, are not legally binding and the school will still be obligated by law to provide compensation for damages.

\section{Transportation of Learners}

Although the majority of South African learners currently utilise public transport, there are a number of learners whose parents bring them to and fetch them from school. In this regard, Section 5.10.1 of the Department of Education's Guidelines to ensure quality education and support in special schools and special school resource centres (2007a) states that a special school must provide transport for all those learners who require transport in order to be enable them to access the school. The guidelines further recommend that the transport subsidy for special schools, both residential and non-residential, should be evaluated regularly to ensure adequacy. Furthermore, transportation companies that convey learners to and 
from school should register with the school, since their activities are interconnected with those of the school. In this regard, the Department of Basic Education's Regulations for Safety Measures at Public Schools (Department of Basic Education, 2007, schools must ensure that the following conditions are met:-

1. The drivers of such vehicles are in possession of valid driver's licences and professional driving permits.

2. The transport company or the owner of the vehicles provides the school with the following:

a. Insurance and roadworthy certificates for each vehicle;

b. Passenger liability insurance documentation.

3. The vehicle transporting learners has a fire extinguisher.

Additionally, certain challenges are posed when learners are dropped off outside the school premises since somebody needs to monitor them until they enter the school. Schools should thus ensure that all learners (including both those who use public transport and those who are transported by their parents) are both dropped off and collected inside the school yard to ensure their safety before and after school.

\section{Workshops and Craft Centres}

Learners are taught practical skills such as woodwork in school workshops and craft centres. Whilst these are very valuable skills to impart to learners with intellectual disabilities, the kind of equipment and substances involved in such activities can pose serious threats to learners' safety. In terms of the South African Occupational Health and Safety Act (85 of 1993), learners, like employees, are entitled to a safe working environment and it is the school's duty to ensure that potential hazards and risks are eliminated or at least mitigated (Republic of South Africa, 1993). Woodwork tools like saws, jointers, boring machines and the like can cause injuries if learners do not use them properly and the noise and sawdust that they produce can also be detrimental to learners' wellbeing. Learners with strong allergies can develop serious respiratory problems such as chronic bronchitis if they are repeatedly exposed to sawdust and persistent exposure to loud noises can cause permanent damage to learners' hearing. Therefore, personal protective equipment (PPE) such as dust masks, respirators and earmuffs must be provided to learners under the supervision of educators to ensure the proper use of PPE and adherence to sound health and safety practices.

\section{Garden}

At the special school where this study was conducted, as part of the focus on gardening as a learning area in the curriculum, each learner is assigned a portion of the school yard in which to cultivate a garden. As with woodwork, this valuable practical learning experience does pose some safety hazards. Garden tools such as spades, garden forks, and hoes used to loosen the soil can be dangerous; especially when they are used by intellectually disabled children. Learners working in the garden thus need educator supervision to minimize the risk self-injury and injuring to others. Additionally, the proper PPE, such as gloves and safety boots, must be provided to learners to further minimise the risk of injury.

\section{Road Safety}

The special school in the study is situated in a rural area along a main road, which learners coming from the village have to cross in order to gain entry to the school. This situation poses a serious threat to learners' safety as there are no traffic signs or road markings to clearly indicate a pedestrian crossing, and there is no scholar patrol on duty to assist learners in crossing the road before and after school. This situation is especially disconcerting if one considers the fact that intellectually disabled learners often need more assistance in such situations than their able-bodied counterparts do. This is yet another instance by which we are reminded that even learners with only mild intellectual disabilities have significant difficulty in effectively managing their lives without sufficient support and training.

\section{Access to School Premises}

All schools ought to have well-trained security guards at their points of entry to control access to the premises. Security guards employed in special school must receive additional training on how to interact with intellectually disabled learners (Department of Basic Education, 2007b). All people entering the school premises are subjected to searches. It is advised that visitors be required to produce identity documents and provide their details before they are granted entry to the school. 
Collection of children from the school must also be monitored to ensure that the right child is collected by the right parent or designated person. The school will be held liable if any child goes missing during school hours.

\section{RequirementS for safe environmentS in Special schools}

\section{Trained staff}

The Department of Basic Education's Guidelines to ensure quality education and support in special schools and school resource centres (2007b) advocate that staff in special schools should include professional teaching staff as well as professional and non-professional support staff to ensure a learning environment and support structure suitable for children with special needs.

\section{Professional Teaching Staff}

Special schools require well trained professional educators who are specifically qualified to teach intellectually disabled learners. The safety and scholastic development of intellectually disabled learners can be jeopardised if they are supervised by educators who know nothing about their needs. Prospective staff members must be thoroughly screened before they are appointed to ensure that they suitable to work with children with special needs (Department of Basic Education, 2007b). According to the aforementioned guidelines (Department of Basic Education, 2007b), professional teaching staff should have the following skills if inclusive education is to be supported:

- A first degree or diploma, which includes training on special needs or inclusive education;

- $\quad$ Training in the development of Inclusive Learning Programmes;

- $\quad$ Engagement in ongoing professional development related to the needs of the learners;

- $\quad$ Competence in the methods of communication utilised by the learners in the school.

It is also recommended that learning support teachers and teaching assistants be included on the teaching staff. Special schools should adhere to the teacher-learner ratio recommended by the Department when appointing teachers.

\section{Psychologists}

Individuals with intellectual disabilities often also suffer from associated mental illnesses (Intellectual Disability Rights Service, 2009) and the therefore require the support of a psychologist. Psychologists can easily diagnose and assess the nature of both the intellectual disability and the mental illness and subsequently recommend the most appropriate modes of support. At times, intellectually disabled people may have more than one disability that, in the absence of a psychologist to make a proper diagnosis, often goes undetected. It should be noted that a single psychologist can be appointed at District level to oversee a number of special schools rather than focus on just one school. Through partnership with psychologists, special schools can ensure optimal safety and support for all learners, since each learner's particular needs can be identified and understood.

\section{Social Workers}

The services of the social workers are inevitably required when one is dealing with intellectually disabled learners, particularly when those learners demonstrate behavioural problems. Among other services, social workers, like psychologists, can provide counselling to learners. It is the responsibility of the social worker to liaise with learners' parents and guide them to the appropriate support channels. Intellectually disabled learners who pose a threat to the safety of other learners can also be directed to social workers.

\section{Nursing Staff}

As nursing staff are fairly scarce, it is recommended that health professionals be appointed by the District and stationed at special school resource centres to ensure their accessibility to multiple schools (Department of Basic Education, 2007b). More importantly, nurses should be required to pay regular visits to special schools to ensure that prescription medication, where relevant, is being administered correctly. Ensuring the safety of intellectually disabled learners in class and surrounding is not only dependant on educators creating a safe physical environment; learners' internal functioning must also be regulated and this internal regulation is often performed by medication. 


\section{Recommendations for a Maintaining a Safe Special School Environment}

Schools should draft simple posters outlining their safety policies and procedures and display these in all classrooms. This will assist in maintaining a risk-free environment for staff and learners. Unsafe conditions must be identified and reported to the school office immediately. It is the responsibility of educators to provide sufficient supervision in the classroom. Under no circumstances should intellectually disabled learners be left unattended in the classroom or on the school grounds. As such, principals should refrain from calling educators to the office during class time and staff meetings should be scheduled for after school, once the learners have already gone home. Additionally, the security of the building and perimeter fences should be checked regularly.

\section{Discussion of Findings}

\section{Inadequately Qualified Educators}

The researchers found that, of the 22 teaching staff members employed the school, only four had qualifications specialising in inclusive education. Eighteen of these educators only had generic three-year teaching qualifications, with only the aforementioned four teachers being qualified at NQF Level 8 . The challenge was that it was not easy for the four relevantly qualified teachers to guide or teach the other 18 staff members how a special school should be run. These less qualified staff members were frustrated by the need to teach these learners in a more holistic way than they had been trained to do. As Hetler (1980) explains, for all wellness requirements to be satisfied at a special school, teachers need to make sure that every learner's intellectual, emotional, social, physical, and spiritual potential is unleashed in addition to preparing them to be eligible for employment upon completion of their schooling. Teachers expressed their desired for skills development interventions to better prepare learners for gainful employment. The challenge is to prepare students to enter the workforce by the time they graduate at age 21 so that they can support themselves financially, without having to rely solely on government disability grants. Furthermore, teachers were worried about the teacher-to-learner ratio in their classrooms, with the large class sizes making it difficult for them to supervise learners properly. As such, they expressed the need for assistant teachers to be employed at the school to provide support in this regard.

\section{Safety Concerns related to Learner Transportation}

The study revealed that almost half of the learner population used public transport facilities to travel to and from school. It was clear that the school's minibus was not sufficient to transport all learners. Learners from neighbouring villages travelled on the backs of bakkies (small trucks) with canopies not designed or intended for this purpose but rather for the transportation of goods. Due to socioeconomic constraints, parents had no choice but to depend on this highly unsuitable and even dangerous mode of transportation for their children. Sadly, no staff member raised the issue of the clear need for a school learner transportation service, despite the fact that they were all aware of these issues and many even transported learners themselves. This situation is clearly having a very negative impact on learner safety.

\section{Safety Concerns in Workshops and the Garden}

Learners in the various skills classes were grouped according to their abilities and interests in order to prepare them for the most suitable careers. Unfortunately, the classrooms, workshops and outdoor spaces where welding, electrical work, carpentry, needlework, and gardening skills were taught only accommodated learners with mild intellectual disabilities. In other words, only those learners who possessed of the intellectual capacity to understand workshop safety practices and to take the necessary precautions were truly safe in these environments. Nevertheless, it was encouraging to discover that all learners were supervised by teachers at all times in these environments. This is significant as the inadequate safety precautions made it necessary for an adult present to prevent accidents. With regard to gardening, teachers encountered the challenge of learners wanting to water the garden during teaching periods when they became bored with academic subject matter. Teachers allowed this, despite the risk involved in these learners being left unattended.

\section{The Importance of Effective Feeding and Health Schemes}

Kwatubana and Nel (2014) assert that a health-promoting school eliminates health hazards in the school and its surrounds. The school in question indeed complied with such a definition of a health-promoting school. The kitchen where food was prepared was clean, despite water shortages, thanks to the diligence of the kitchen staff. Learners also washed their hands 
before they ate their meals and teachers supervised the serving process as well as the collection of dirty dishes. No learner was allowed to eat while standing or outside of the classroom in order to ensure close monitoring. School meals were especially important because some of the learners only ate at school due to impoverished home environments. The vegetable garden in the school premises meant a great deal because learners knew that, after the harvest, their crops would form part of their meals. Hence, they took special care of the garden and watered it regularly.

\section{The Need for a Functional Roster for Playground Supervision}

The only formal roster that was availed to researchers was the one used for formal sports training or when there were matches at the school premises. Most often, due to staff shortages, children played alone on the sports field with no supervision during break times. Teachers complained that they were supervising children who were eating in the classroom and were unable to supervise those playing outside the classrooms. This poses a serious challenge to teacher learner ratio at a special school for learners with intellectual disabilities.

\section{Intervention}

Since the project involved both research and the community, it was necessary to perform the research before sharing the findings thereof with the SMT and teachers. The nature of the project called for action research, which is more concerned with practice than with theory (Townsend, 2010). Furthermore, as Wood (2014, pp. 667) asserts:

Action research contributes to improving social situations, while simultaneously generating knowledge that can influence educational practice and research in a significant way.

The researchers asked the school management team to outline their needs and where they needed immediate intervention. Their immediate needs lay in the area of teacher roles and responsibilities regarding supervision and to help teachers to understand their in loco parentis responsibilities. To address this, the researchers organised a workshop for the entire staff on supervision and in loco parentis responsibilities in relation to the various roles pertinent to learner safety within the school premises.

The intervention was initiated in terms of holding a number of workshops in areas where knowledge and training gaps has been identified. The workshops covered transport safety, safety in workshops, hygiene and health matters, and children's rights in general. Evaluation was done to measure how successful the intervention workshops were and the findings were satisfactory in that they initiated a reasonable change at this special school.

\section{Transport and Safety}

The first workshop was on the safety of the learners during their transportation between their homes and the school. Some of the learners travelled in vehicles of various descriptions, whilst others who lived in the village simply walked to school. Neither road signage nor road markings were in place to inform drivers about children that are crossing the road from the village. To ensure the implementation of adequate solutions, the school management team included this item in their parents meeting so that the issue of safe learner transportation was thoroughly discussed and addressed. Some parents volunteered to monitor the transport used by the learners in addition to ensuring that the rules of the road were respected.

\section{Safety in Workshops and the Garden}

The school has the following workshops: welding, carpentry, bricklaying, and electrical work. In all of these workshops, certain precautions must be taken to eliminate the risk of injury. The second workshop was thus on safety in the workshops, where learners are exposed to hazardous substances such as dust, heavy machinery, and hand tools. Safety rules and warning signs were posted on the walls of the workshops and these rules were explained to and continually reinforced with learners each time they entered the workshops.

Meanwhile, in response to concerns with regard to the safety of learners while gardening, teachers were made aware of the importance of supervising learners when they are using garden tools and pesticides, and even when they lay fertilizer. The school did not have a garden and so the researchers assisted the teachers and all the learners who were interested in planting one. These interested teachers and learners were also given training by a facilitator organised by Unisa's Chance2Advance initiative. One of the primary values of this initiative was its strong ability to prepare learners for career wellness. Subsequent to receiving the training on gardening, two learners from the school found employment in this field in the nearby town. 


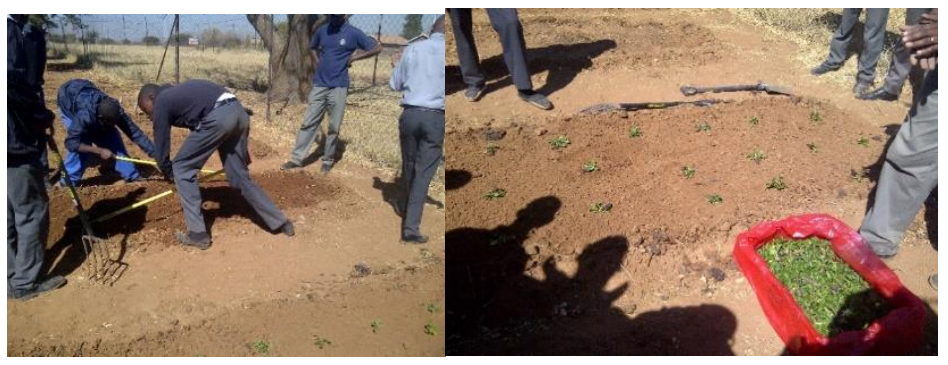

Image 1: Learners under supervision of teachers and facilitator on how to start a crop garden

(2013 Unisa Community engagement intervention)

\section{Teacher and SMT Roles}

The whole responsibility of ensuring a safe environment in school is vested in the school management team (SMT). The researchers therefore instituted the intervention initiative of training the SMT on learner supervision. The training was aimed at making the SMT aware of its duties and responsibilities as expected in terms of its in loco parentis role; i.e. teachers are required to honour their duty to care for learners as bonus paterfamilias. This duty begins when the first learner arrives at the school in the morning and continues until the last learner leaves the school in the afternoon. It is extended to a few meters beyond the school yard, within the vicinity of the school. Each educator's duty to care for learners must be included in his or her job description, to remind him or her that it is their lawful obligation. When drawing up the school duty roster, the SMT must ensure that it indicates the names of teachers who are on supervision duty at the school entrances and surrounding areas.

As mentioned, sports ground supervision is of also paramount importance in special schools. Classes left without an educator descend into chaos, especially in the case of learners with special needs. Teachers were encouraged to implement what they had learnt and informed that, after three months, the research team would return to the school to evaluate the safety measures put in place.

This intervention will benefit the school in that teachers now understand their roles regarding learner safety at the school and will practise what they have learnt. Moreover, the school management team will be able to allocate teacher duties (especially those that involve learner supervision at break times) more appropriately and effectively. It will also benefit the learners in that the teachers will be more careful in dealing with safety issues that impact them in the future.

\section{Career Wellness}

Since teachers expressed concerns about how to prepare learners for future careers, the researchers organised facilitators for to train the learners in computer literacy and pedicure and manicure skills. The teachers were also trained in those skills so that they could supervise learners during their practical activities for those subjects. The training was done over a period of five days from $08 \mathrm{~h} 00$ to $14 \mathrm{~h} 00$ each day. All those who attended training received certificates from Chance2Advance. For teachers, this training was credited as continuous professional development.

\section{Evaluation after Three Months}

After a period of three months, the researchers visited the school in order to give support and guidance where necessary. It was found that the teachers and the school management team had sought sponsors to buy the necessary material where they needed to improve their situation. They had also advertised posts for teachers with various skills in promoting career wellness for learners with intellectual disabilities. Workshop environments had become far safer. Although there was a lack of some items like safety boots, the school had managed to obtain safety hats for bricklayers, glasses for welders, and two sewing machines. The school's training hair salon was also equipped with the necessary supplies. The SMT and teachers were applauded for their initiative in these areas. The crop garden had improved significantly and learners took great pride in the sense of ownership and achievement they derived from planting and tending to the garden when they saw the crops growing. The vegetables from this garden were harvested and cooked as part of healthy break-time meals for learners. In 
this way, physical wellness was promoted, with the garden initiative contributing towards healthy eating patterns for the learners.

The following images demonstrate some of the successes achieved through the action research project at this school.

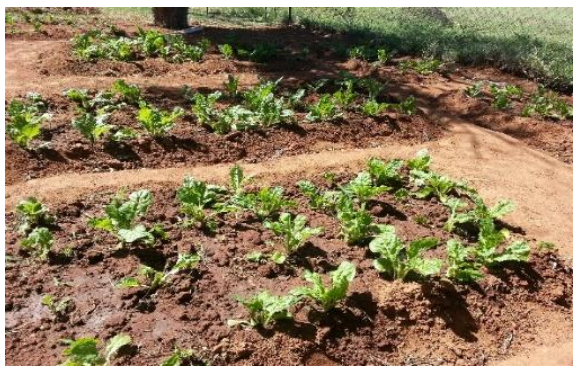

Image 2. An improved garden after three months

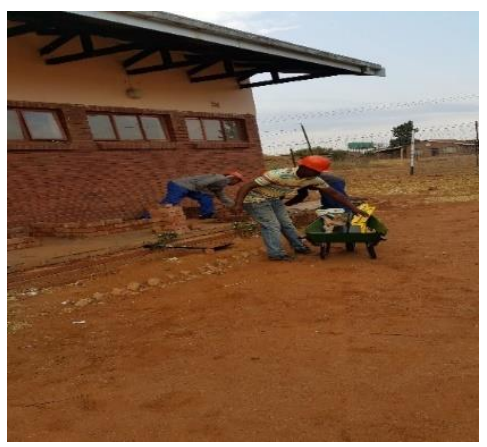

Image 3. After a while, bricklayers had the material to use and all had safety hats

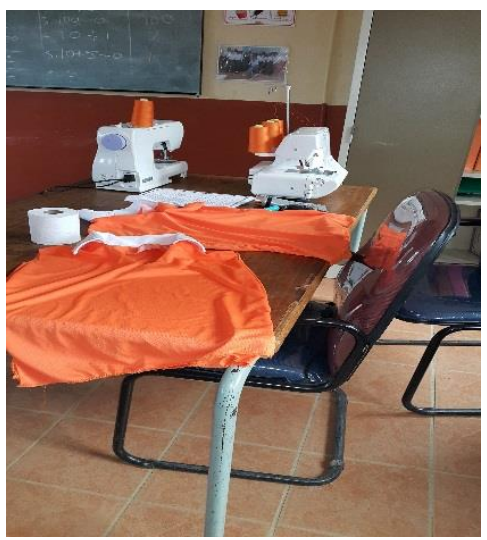

Image 4. Two sewing machines were secured and learners sewed their own netball uniforms 


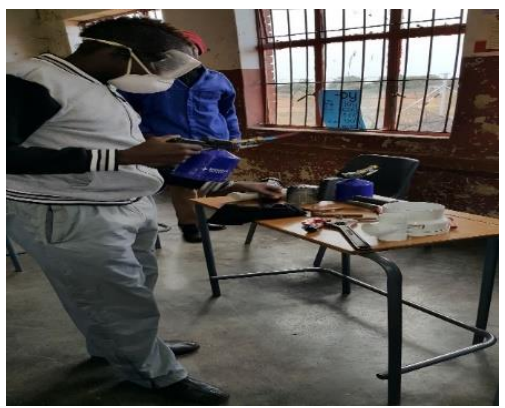

Image 5. Protective/safety glasses were worn by learners when welding

\section{Conclusion}

This chapter has repeatedly emphasised the fact that learners have the right to basic education in terms of Section 29 of The Constitution (Republic of South Africa, 1996a). This right can only be fulfilled in a safe school environment. The intervention was thus framed within the essence of education law embedded in the German concept of geborgenheit. Cassells (as cited in Oosthuizen, 2009, pp. 16) explains that, in the German language, the term infers more than its direct English translation as "security"; it encompasses a web of concepts including "salvage", "salve", "save", "rescue", "shelter", "shield", "hide", "conceal", "being saved", or "being in safety". Teaching and learning for children can only take place in an environment that is free of fear and the risk of harm.

Learners' wellness in all dimensions is crucial irrespective, of their situation or abilities. Nevertheless, the current study demonstrated the particular need for holistic development for learners with intellectual disabilities. The researchers, in using action research, were able to support the school management team and teachers by intervening where information, training and infrastructure gaps were identified. The school also realised its need to seek help and support from other organisations so that the learner is developed holistically. As the old expression goes, "it takes a village to raise a child". Indeed, special schools need an extensive network of stakeholders in order for all the wellness needs of learners to be met. In action research, lessons learnt for participants promote self-reflection and the development of problem-solving skills (ZuberSkerrit, 2011) that promote lifelong learning. The efforts of teachers to outsource skilled teachers and resources has greatly benefited the school and enabled it to improve despite the challenges inherent in its rural location. When learners exit the school at the age of 21, they will be adept in one or two key skills, imparted to them during through this holistic approach to their education.

\section{References}

[1] Barry, B. (2006). Schools and the law. Cape Town: Juta and Company.

[2] Coetzee, S. A. (2007). Legal issues in educational leadership. Pretoria: University of South Africa.

[3] Criminal Justice Support Network. (2009). Intellectual Disability Rights Service. Retrieved October 2, 2016, from http://www.idrs.org.au/home/index.php

[4] Department of Basic Education. (2007a). Guidelines to ensure quality education and support in special schools and school resource centres. Pretoria. Government Printers.

[5] Department of Basic Education. (2007b). The regulations for safety measures at public schools. Pretoria. Government Printers.

[6] Henning E, Van Rensburg W \& Smit B. (2004). Finding your way in qualitative research. Pretoria. Van Schaik.

[7] Hetler, B. (1980). Wellness promotion on a university campus. Family and Community Health, 3, 77-95.

[8] Intellectual Disability Rights Service (2009) Introduction to intellectual disability. Retrieved October 2, 2016, from: http://www.idrs.org.au/education/about-intellectual-disability.php

[9] Joubert, R. (Ed.). (2015). The law of education in South Africa. Pretoria: Van Schaik

[10] Kwatubana, S. \& Nel, M. (2014). Health promotion in South African schools. In M. Nel (Ed.) Life Orientation for South African Teachers (pp.). Pretoria: Van Schaik Publishers.

[11] Myers, J. E., Sweeny, T. J. \& Witmer, J. M. (2000). The wheel of wellness counselling for wellness: a holistic model for treatment planning. Journal of Counselling and Development, 78, 251-266. 
[12] Oosthuizen, I. J. (Ed.). (2009). Aspects of education law. Pretoria: Van Schaik.

[13] Prinsloo, S. (2015). Human rights in education. In R. Joubert (Ed.). The law of education in South Africa. Pretoria: Van Schaik.

[14] Republic of South Africa. (1993). Occupational Health and Safety Act (85 of 1993). Pretoria: Government Printers.

[15] Republic of South Africa. (1996a). Constitution of the Republic of South Africa (Act 108 of 1996). Pretoria: Government Printers.

[16] Republic of South Africa. (1996b). South African Schools Act (84 of 1996). Pretoria: Government Printers.

[17] Republic of South Africa. (2005). Children's Act (No. 38 of 2005). Pretoria: Government Printers.

[18] Roos, M.C, Oosthuizen, I.J \& Smit, M.H. (2009). In Oosthuizen, I. J. (Ed.). Aspects of education law. Pretoria: Van Schaik.

[19] Townsend, A. (2010) Action research. In Hartas, D. (Ed.). Educational research and inquiry. Qualitative and quantitative approaches (pp. 131-144). London: Continuum.

[20] United Nations. (2007). Optional Protocol to the Convention on the Rights of Persons with Disabilities, New York, 13 December 2006, GA/RES/61/106 (2007), Annex II. Retrieved October 2, 2016, from http://www.un.org/disabilities/documents/convention/convoptprot-e.pdf

[21] Van Lingen, J. M. (2000). Perspectives on wellness amongst students at the University of Port Elizabeth. (Unpublished doctoral thesis). Nelson Mandela Metropolitan University, Port Elizabeth, South Africa.

[22] Wood, L. (2014). Action research for the $21^{\text {st }}$ century: Exploring new educational pathways. South African Journal of Higher Education, 28(2), 660-672.

[23] Zuber-Skerrit, O. (2011). Action leadership: towards a participatory paradigm. Dordrecht: Springer International. 